\title{
CINCO INSCRIPCIONES LATINAS DEL TERRITORIO DE DIANIUM (DENIA, ALICANTE. HISPANIA CITERIOR)
}

\author{
JUAN MANUEL ABASCAL \\ Universidad de Alicante \\ JOSEP ANTONI GISBERT \\ Museu Arqueològic de Dènia
}

\begin{abstract}
Este artículo contiene las novedades epigráficas del territorium de Dianium, así como la descripción de un viejo texto, que se creía perdido, procedente de Pego.

This item is about the last inscriptions found in the Territorium of Dionium and about the description of an old text from Pego, which was thought to be lost.
\end{abstract}

El territorium de Dianium incluyó en la Antigüedad buena parte de la región natural conocida hoy como la Marina Alta y fue uno de los más septentrionales en la costa del conuentus Carthaginensis. El volumen de hallazgos arqueológicos registrado en este área crece de manera permanente y permite imaginar una zona con un alto índice de implantación rural en la que jugó un papel importante la producción de vino y aceite. El núcleo urbano obtuvo el rango jurídico municipal probablemente a comienzos de siglo. El conjunto epigráfico del territorium incluye 41 textos (ABAD y ABASCAL 1991, 125, n. ${ }^{\circ} 75 \mathrm{ss}$.), a los que hay que añadir cuatro de los que ahora presentamos, ya que uno de ellos, el procedente de Pego (n. ${ }^{\circ}$ 2), era ya conocido con anterioridad (Figura 1).

\section{Pedreguer (Alicante). Inédita. Figura $2^{\prime}$.}

Bloque en caliza arenosa de color ocre hallado en 1978 al realizar labores de transformación en una parcela de la partida Mirabó en el término de la localidad de Pedreguer (Alicante). El soporte presenta incrustaciones de orbitalinas cretácicas que afloran en las estribaciones de La Sella y en la sierra del Montgó; se trata, por tanto, de un material de procedencia estrictamente local.

\footnotetext{
' Fotografías e ilustraciones de J.M. Abascal.
} 


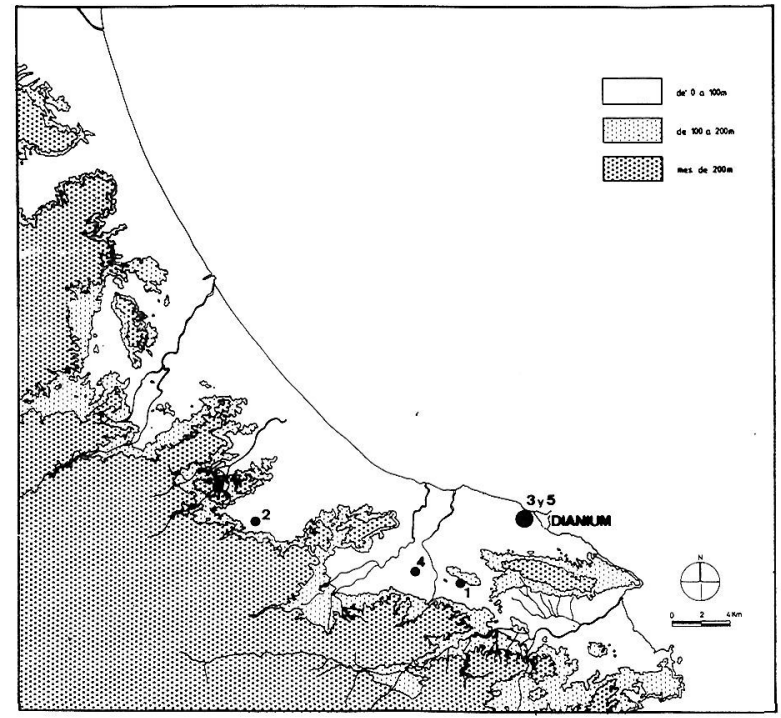

Fig. 1.- Plano de la zona de procedencia de los nuevos epígrafes.

El lugar de hallazgo es una parcela ubicada al sur de la estribación más oriental de La Sella, elevación montañosa con cotas de hasta 231 metros de altitud, en zona de piedemonte, y se sitúa junto a un camino rural que discurre entre las partidas de Montroig y Mirabó, frente a la «Caseta del Virgo», un edificio rural del siglo XIX. El camino de acceso a la parcela arranca en las proximidades del kilómetro $193 \mathrm{de}$ la carretera nacional $332\left(38 .^{\circ} 47^{\prime} 58^{\prime}\right.$ ' de latitud norte y $3 .^{\circ}$ 44' $37^{\prime \prime}$ de longitud respecto al meridiano de Madrid, Hoja 822 I de la cartografía militar de España 1:25.000).

La prospección detallada de la zona (noviembre de 1993) arrojó resultados negativos, por lo que podría considerarse un hallazgo aislado. El área de la que procede el monumento presenta una importante densidad de yacimientos arqueológicos de época romana, en su mayoría datables a comienzos del Principado; se pueden destacar entre ellos la villa romana de Montroig (Pedreguer, Alicante) situada a unos 1.400 metros hacia el sudeste, y el asentamiento rural de Els Oquins, en el mismo término y ubicado unos 1.300 metros al sur del lugar del hallazgo.

El soporte se encuentra fracturado en todos sus lados y presenta numerosas erosiones en su superficie (descripción del soporte realizada en Denia el 23 de octubre de 1990). El texto, en consecuencia, tiene carácter fragmentario. Sus dimensiones son $53 \times 42 \times 28 \mathrm{~cm}$; el campo epigráfico coincide con las medidas del soporte y conserva 6 líneas de texto. Las letras son capitales de buena factura, ligeramente deformadas en origen por las características de la piedra y de incisión profunda; su altura oscila en todos los casos entre 4'5 y $4 ' 9 \mathrm{~cm}$, con una interlínea uniforme en torno a los $2-2^{\prime} 5 \mathrm{~cm}$;

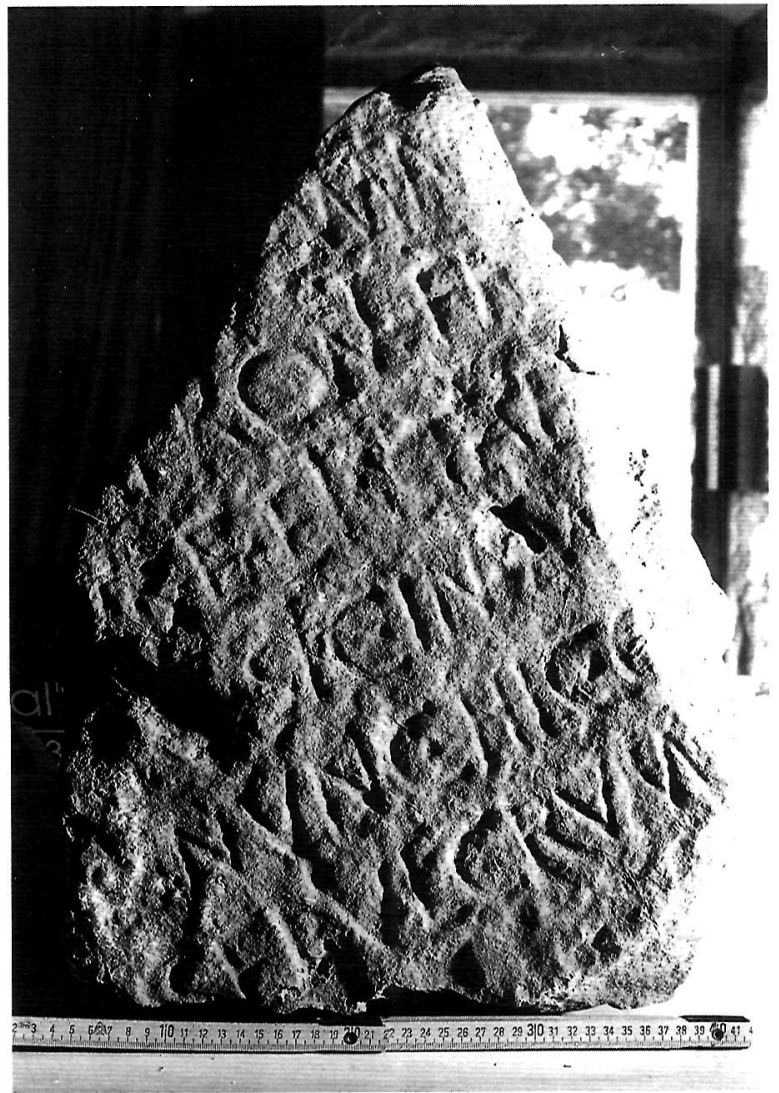

Fig. 2.- Inscripción de Pedreguer (n. $\left.{ }^{\circ} 1\right)$

las excepciones son las I longae de $1.2\left(5^{\prime} 5 \mathrm{~cm}\right)$ y $1.4(6 \mathrm{~cm})$, así como la T longa de $1.3(6 \mathrm{~cm})$. Presenta interpunciones triangulares con el vértice hacia arriba.

La rotura de la parte izquierda del texto impide reconocer otros posibles rasgos en las líneas 3, 4 y 5 . No hay posibilidad de calcular la longitud perdida por la derecha en ninguna de las líneas. En la quinta, una ordinatio poco previsora obligó a colocar las interpunciones dentro de las consonantes.

En el final de la segunda línea una pequeña rotura horizontal disfraza como R lo que en realidad es la I de filius, a la que sigue un resto muy leve del trazo vertical de la $\mathrm{L}$, por lo que no hay duda de que estamos ante una filiación.

$\mathrm{Al}$ comienzo de la tercera línea conserva un asta vertical, seguida de una letra perdida y de una E. Al comienzo de la cuarta línea figura un trazo oblicuo de A o R entre dos espacios de letras perdidas antes del gentilicio Sicinius; dado que este rasgo no parece pertenecer a un praenomen, hay que descartar aquí un tria nomina. Al final de la quinta línea aparece una letra redonda rota por la derecha, por lo que las opciones C, O, Q serían válidas; sin embargo, al tratarse ya de parte del 


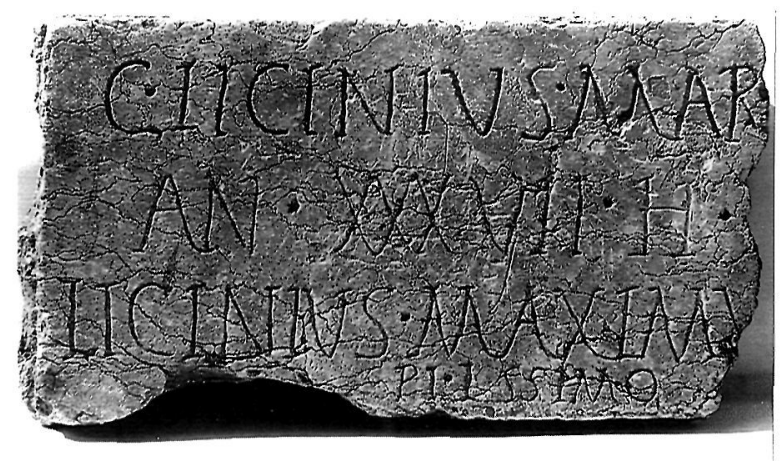

Fig. 3.- Inscripción de G. Licinius Marinus en Pego (n. ${ }^{\circ}$ 2).

formulario funerario y figurar tras los dos adverbios, hemos optado por entender aquí una forma verbal y no un plural como ossa, que también habría sido posible.

Tras las gestiones realizadas por D. Joaquim Bolufer, el propietario del terreno, D. Pascual Noguera, la donó en 1990 al Museu Arqueològic de la Ciutat de Dénia, en donde actualmente se conserva. El texto dice:

$$
\begin{aligned}
& {[---] \text { OMN[---] }} \\
& {[--- \text { Se]mproni fi[lius ---] }} \\
& {[---]++ \text { e et G(aius) Ae[---] }} \\
& {[---]+[-] \text { Sicini M[---] }} \\
& {[---]+\text { s nunc hic q[uiescunt---] }} \\
& {[---] \text { sepulcrum [--- }} \\
& {[---]}
\end{aligned}
$$

\section{2 y L.4: Nexo NI con I longa}

Pese al carácter fragmentario del texto, da la impresión de que estamos ante el monumento funerario de, al menos, tres personajes, cuyos nombres completos no podemos restituir ya que de dos de ellos sólo conservamos parte de la filiación.

El gentilicio latino Sicinius (SOLIN \& SALOMIES 1988, 171) aparece por séptima vez en inscripciones de la Península Ibérica. Los testimonios anteriores proceden de Carthago Noua (Sicinia Q.f.: EE 8, 194 + HAE 122; Sicinia C.F. Secunda: EE 8, 194 + HAE 123), Iluro (Sicinia p.f. Germ[---] y P. Sicinius P.1. Germ[---]: IRC I 106), Jerez de la Frontera (Cádiz) (Sicinia Q.f. Tuscilla: AE 1965, 68) y de la propia Dianium (P. Sicinius P.l. Eutychus, medicus: CIL II 3593); en esta última ciudad, la condición libertina de este medicus prueba la existencia de un grupo familiar que el nuevo texto viene a confirmar.

Los Sempronii también son un grupo bien conocido en el área de Dianium, en donde ya disponíamos de los testimonios epigráficos sobre Sempronia L.f. Campana (CIL II 5964), L. Sempronius Enipeus (CIL II 3583 + p. 958), M. Semproniu[s

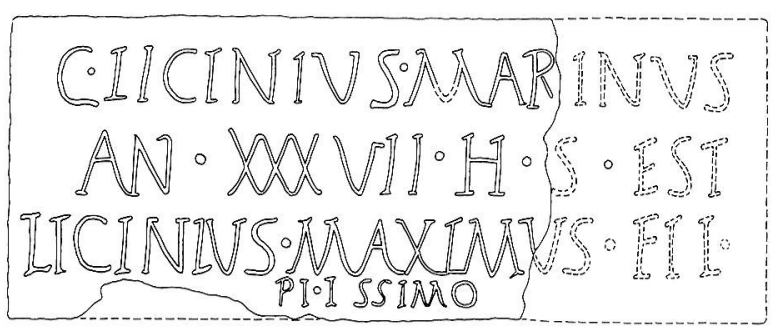

Fig 4.- Restitución del texto perdido en la inscripción de Pego $\left(\mathrm{n}^{\circ} 2\right)$

--]dus (CIL II 3590) y Q. Semproni(us) Q.f. Gal. Taurus (CIL II 3592).

No hay seguridad sobre el gentilicio del personaje mencionado en la tercera línea, que pudo ser tanto Aelius como Aemilius; en la primera opción sólo podría invocarse su relación con el individuo mencionado en el tercero de los textos que presentamos, mientras que el nomen Aemilius ya es conocido en otros textos de la ciudad.

La mayor dificultad del epígrafe estriba en dar sentido a la primera línea. Desde el punto de vista de la onomástica las soluciones no parecen fáciles, pues fuera de alguna rareza como Domnina o Theomnestus no es fácil justificar el grupo $\mathrm{OMN}$ —dentro de un antropónimo; más sentido parece tener en un pronombre como omnis en cualquiera de sus casos, lo que induciría a suponer al comienzo de la inscripción una consideración general sobre los personajes citados, bien fuera a una actividad profesional o actividad pública, bien a un collegium, etc.; cualquier consideración en este sentido no sería más que un inútil ejercicio especulativo sin respaldo alguno.

El tipo de letra así como la forma y posición de las interpunciones, a falta de obstáculos en el contenido, aconseja datar el texto en la primera mitad/mediados del siglo I d.C.

\section{Pego (Alicante). Figuras 3 y 4.}

FITA 1908, 508-509; GISBERT 1980; MAULEON 1983, n. ${ }^{\circ}$ 1.775; RABANAL Y ABASCAL 1985, 237, n. ${ }^{\circ} 105 ;$ ABAD Y ABASCAL 1991, 155-156, n. ${ }^{\circ} 113$.

Placa en piedra caliza rosácea de aspecto marmóreo de tipo Buixcarrot, con manchas e irisaciones blanquecinas. Fue descubierta a comienzos de siglo en la «Heretat de Sala», antes denominada de Camacho, en término municipal de Pego (FITA 1908, 508); la finca, de gran extensión, está situada al sur del actual casco urbano, a unos 500 metros del mismo, aunque no se puede precisar el lugar exacto del hallazgo. El área está delimitada al oeste por el Barranc de Sant Xoxim (Sant Joaquim) y se extiende por la vertiente y piedemonte de un macizo montañoso conocido como «Bodoix». Las coordenadas del lugar de hallazgo deben estar próximas a $38^{\circ} 50^{\prime} 4^{\prime \prime}$ de latitud norte y $3^{\circ} 33^{\prime} 57^{\prime \prime}$ de longitud respecto al meridia- 
no de Madrid, Hoja 822 I de la cartografía militar de España 1:25.000; la altitud del terreno está entre los 80 y 100 metros respecto al nivel del mar.

Desconocemos la existencia de otros vestigios arqueológicos en la finca o en sus proximidades. Los hallazgos más próximos están a algo más de $2 \mathrm{~km}$. del enclave y son la villa romana de Sant Antoni (Pego) y la necrópolis con posible asentamiento rural de Favara (Pego), ambos en actividad durante los siglos II y III d.C.

La placa presenta en sus lados una moldura perimetral destinada a facilitar su colocación en algún tipo de monumento; ésta mide 24 ' 5 x $42 \mathrm{~cm}$, mientras que la placa propiamente dicha sólo mide $22 ' 5 \times 41 \times 7 \mathrm{~cm}$. Conserva cuatro líneas de texto cuya altura es de 4'2, 4'3, 4'5 y 2 respectivamente, con una interlínea de 2,2 y $0^{\prime} 5 \mathrm{~cm}$. En las tres primeras líneas conserva profundas interpunciones circulares, mientras en la cuarta, en donde la presencia de éstas era innecesaria, un punto separa las dos primeras vocales del superlativo.

La paginación del texto parece cuidada, centrada y con un correcto diseño previo, pese a que al final de las líneas hemos creido ver alguna alteración en la relación de márgenes. La letra es una capital elegante con tendencia a la cursiva en algunos trazos. No hay uniformidad en el diseño de las letras; así, la $\mathrm{V}$ no tiene el vértice inferior centrado y sus brazos se curvan de desigual manera en los cuatro casos conservados; la A prolonga su extremo inferior derecho en una curva muy abierta que suele cortar el pie de la letra siguiente; el grupo LI de las líneas primera y tercera presenta sensibles diferencias, etc.

La inscripción era conocida desde que en 1908 la publicara Fita a partir de la correspondencia con el abogado valenciano D. Francisco Martínez y Martínez; sin embargo, pronto se perdió su pista incluso antes de ser fotografiada o analizada con rigor. Según Fita, su primer propietario fue D. Roberto Seno Aguilar, vecino de Pego; sabemos que estuvo luego un tiempo en el Aula Museo local bajo la custodia de D. Antonio Pérez. Tras décadas de paradero desconocido, D. Ferrán Naya notificó al Museo Arqueològic de la Ciutat de Dénia que ésta se hallaba en la Casa Abadía de la parroquia de la Asunción de Pego, en donde D. Vicente Peiró, cura párroco, nos ha dado las máximas facilidades para documentarla el día 1 de octubre de 1993. El texto dice:

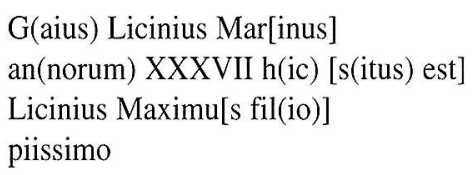

L.1: C(aius), Fita.

L.3: Ligadura MA, Fita.

L.4: TRI PIISSIMO, Fita.

En la restitución propuesta hemos desarrollado la parte final de las líneas a partir del espacio generado por el cognomen de 1.1, en donde con toda probabilidad sólo figuraba el tria nomina del difunto; a partir de ahí, la paginación da pie a no abreviar el verbo en la fórmula funeraria y el centrado de la cuarta línea muestra que el adjetivo es lo único que contiene; esta hipótesis se ve reforzada por la presencia a su izquierda de un espacio libre que sigue a una fractura en la que no hay huella alguna de letras. La dificultad radica en establecer la relación de parentesco entre difunto y dedicante, que debía figurar al final de la tercera línea. Suponiendo que eran reales las letras iniciales transcritas por Fita, sugerimos hace unos años que el difunto fuera padre del dedicante (RABANAL y ABASCAL 1985, 237-, pero hoy día a la vista de la paginación real nos parece probable una restitución como la que presentamos.

Respecto a la identidad del personaje, Fita había relacionado al difunto con el C. Licinius C.f. Gal. Marinus Voconius Romanus amigo de Plinio, que figura sobre una inscripción de Sagunto (CIL II 3866); tal relación a partir de una homonimia no sólo es fantasiosa, sino que encuentra un serio obstáculo en la cronología de este texto.

Los Licinii son un grupo bien conocido y documentado en la costa del sur del conuentus Tarraconensis y norte del Carthaginensis: Sagunto acoge un grupo significativo, con siete testimonios; otros tres proceden de Villar del Arzobispo (Valencia. CIL II 6067; HAE 1425 + HEp 3, 400; HAE 1440 + HEp 3, 410), dos de Lliria (Valencia. CIL II 3805 y 3811) y uno de Carcagente (Valencia. CIL II 3652 + ALFÖLDY 1987, 36, nota 84), Valencia (CIL II 3741), Pilar de la Horadada (Alicante. ABAD y ABASCAL 1991, n. ${ }^{\circ} 116$ ), Alicante (ABAD y ABASCAL 1991, n. ID 18) y Játiva (Valencia. CIL II 3653).

Pese a la vieja suposición de Fita, tampoco existe ninguna relación entre el dedicante del texto, Licinius Maximus, y el P. Licinius P.f. Gal. Maximus que aparece sobre una inscripción de Alhambra (Ciudad Real. CIL II 3230), pese a que el grupo de los Licinii de este núcleo proceden probablemente del área valenciana; la popularidad de los nombres mencionados en el texto impide tomar en serio estas homonimias sin otra base argumental: Maxima/-us y sus diferentes grafías constituyen el cuarto cognomen en importancia numérica de los hallazgos hispanos, con más de 175 testimonios registrados (ABASCAL 1994, passim).

La ausencia de una invocación inicial, el nombre del difunto en nominativo, el superlativo final y el tipo de letra aconsejan datar el texto en los primeros años del siglo III d.C.

\section{Denia (Alicante). Inédita. Figuras 5, 6 y 7.}

Fragmento de una placa honorífica en mármol crema de Valencia con rotura de su esquina superior izquierda y fractura en sus bordes derecho e inferior. Apareció en 1991 forman- 


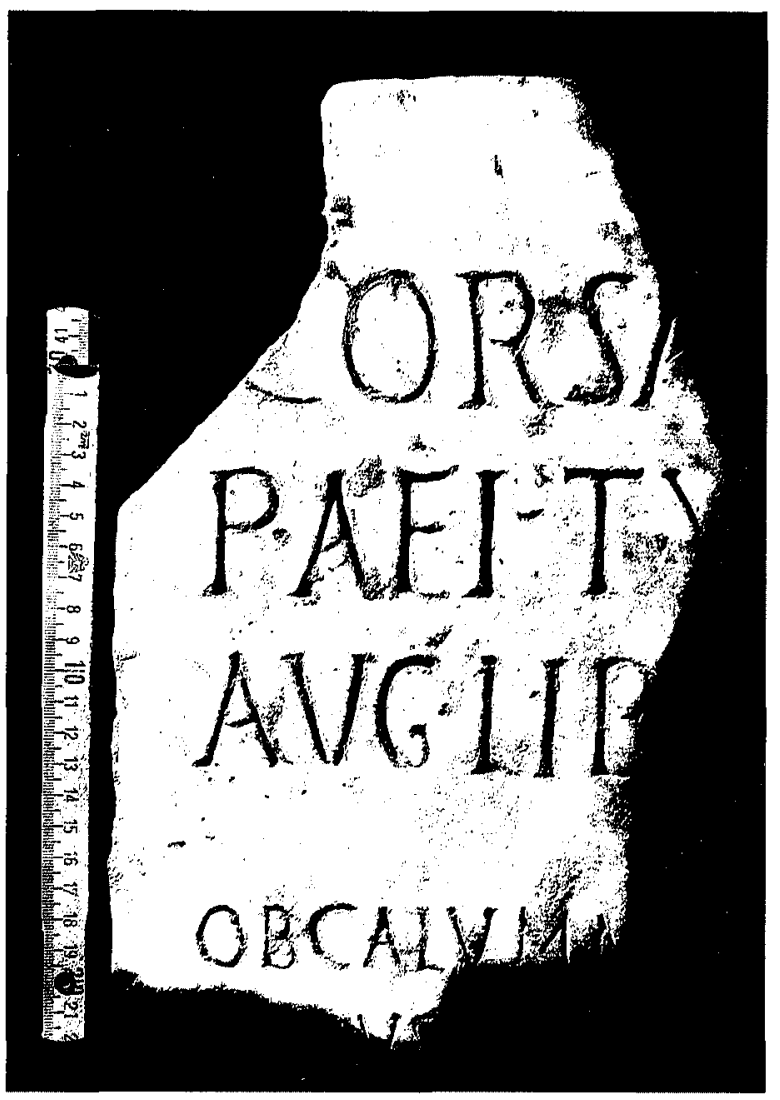

Fig. 5.- Inscripción de P. Aelius Tychius en Denia (n. $\left.{ }^{\circ} 3\right)$

do parte del pavimento de lajas o placas de piedra que rodeaba parte del perímetro de un pozo. Este se encuentra en el lado suroeste del patio de la vivienda ${ }^{\circ}{ }^{\circ} 30$ de la actuación arqueológic «El Forti. Fase III», -DE.C 91-4-. Los trabajos de campo y la excavación fueron dirigidos por D. Marco Aurelio García Bebiá y se integran en el proyecto de investigación «El Forti», que actúa sobre el arrabal islámico de Daniya Denia--. El marco cronológico de esta vivienda es el siglo XII y la primera mitad del siglo XIII. Omitimos la descripción de su contexto arqueológico toda vez que, como material reutilizado, ofrece una información no contrastable con la del monumento que analizamos.

Las dimensiones actuales del fragmento son $31^{\prime} 5 \times 20 \times 3$ $\mathrm{cm}$; conserva un campo epigráfico de $25 \times 16 \mathrm{~cm}$ con cinco líneas de texto partidas por la derecha excepto en la quinta, que sólo presenta dos letras sin contexto. La altura de las letras es 4'2, 4, 3'8, y $2 \mathrm{~cm}$, no pudiendo medirse la quinta, que no alcanza los $2 \mathrm{~cm}$; las interlíneas miden 2, 2, 4'5 y 1'5 cm. La letra es una capital muy próxima a algunos rasgos de actuaria. El texto presenta interpunciones circulares en 1.2 y 1.3 y un rasgo oblicuo en esta última.

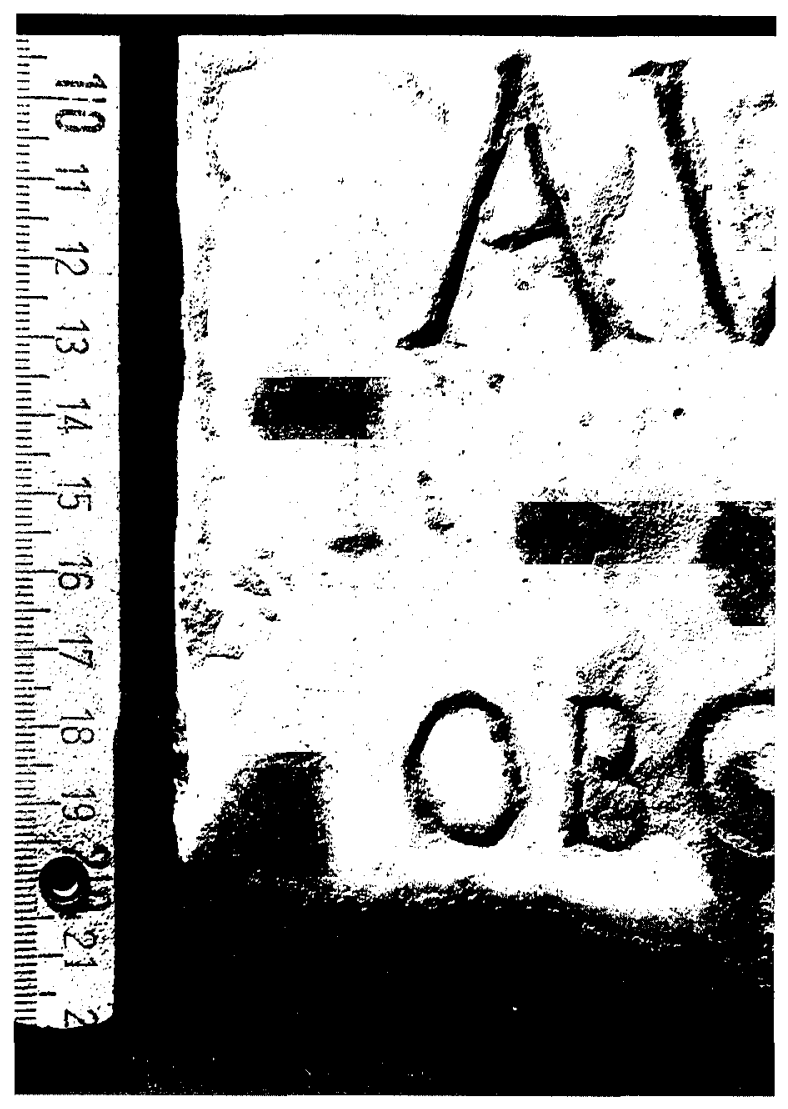

Fig. 6.- Detalle del pautado de la inscripción de Denia (n. ${ }^{\circ} 3$ ).

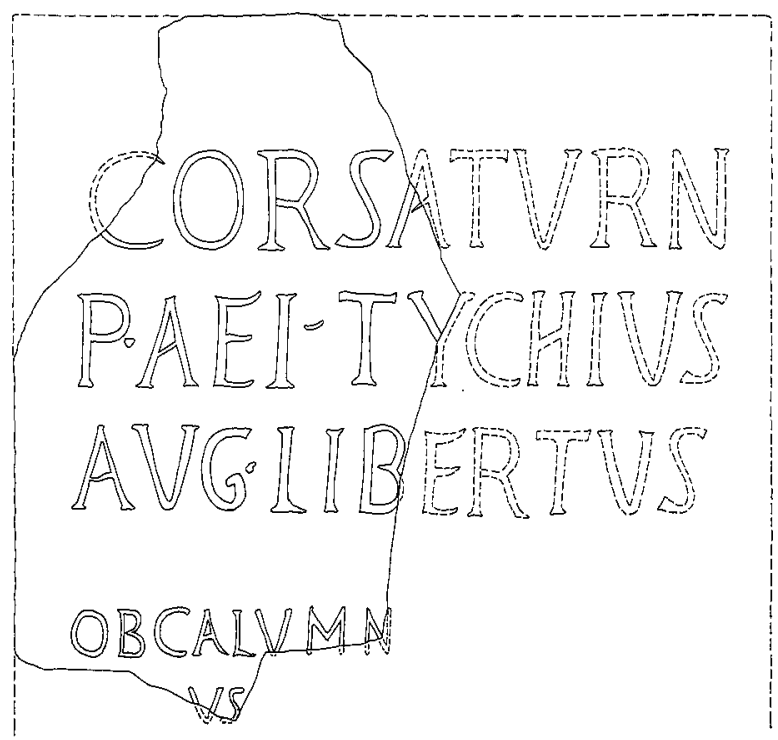

Fig. 7.- Restitución del texto en la inscripción de Denia (n. 3 
En la primera línea el rasgo conservado a la izquierda debe corresponder a una $\mathrm{C}$ y la paginación aconseja la ausencia de praenomen. En la segunda línea el trazo superior derecho de la Y marca la fractura del texto, conservando el bisel de la incisión en el propio canto del soporte. No hay huellas de incisión ni en la primera ni en la cuarta línea, pese a lo cual parece probable el desarrollo onomástico propuesto para el comienzo.

La superficie escrita conserva un fino pautado inciso marcando el campo epigráfico y algunas de las líneas, aunque debido a su escasa profundidad se ha perdido en diversas zonas. Todo el texto está alineado a la izquierda, aunque su probable restitución aconseja suponer unas longitudes de línea muy similares.

El monumento se conserva en el Museo Arqueológico de Denia, en donde lo vimos el día 6 de octubre de 1993. El texto dice:

$$
\begin{aligned}
& \text { Cor(nelio) Sa[turn(ino)] } \\
& \text { P(ublius) Ael(ius) Ty[chius] } \\
& \text { Aug(usti) lib[ertus] } \\
& \text { ob calumn[---] } \\
5 & {[---] V S[---] }
\end{aligned}
$$

El cognomen del dedicante admite diversas alternativas, aunque hemos optado por la perteneciente a un conocido grupo de nombres griegos bien representado en el levante y

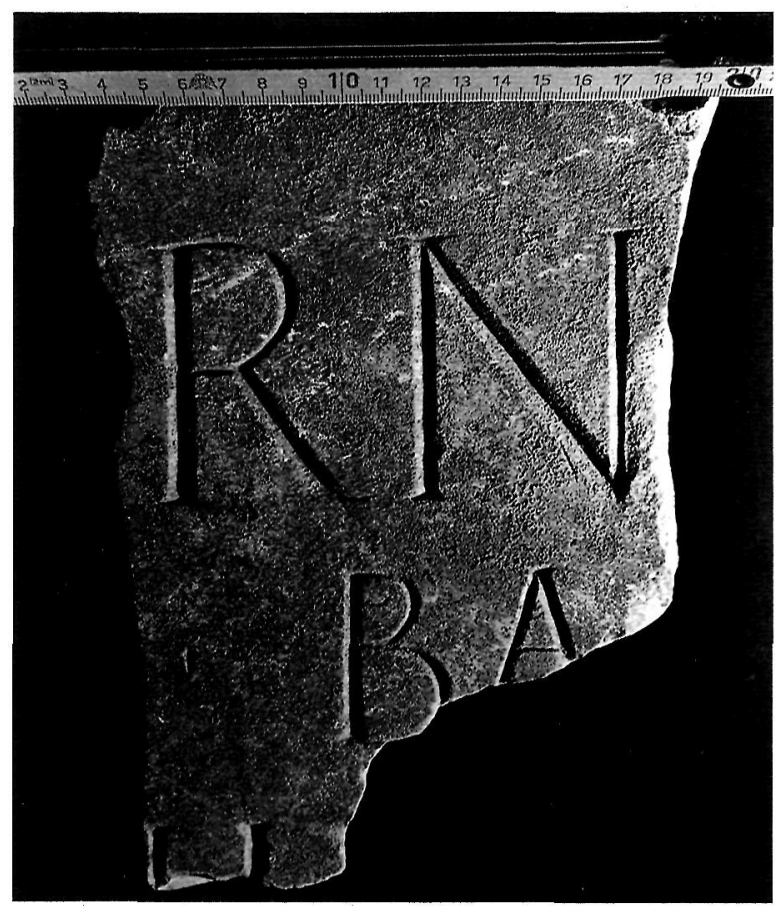

Fig. 8.- Inscripción de Cornelius Bassus en Sanet i Negrals mediodía peninsular. El nombre de origen griego Tychia/-us (SOLIN 1982, 520) aparece en tres ocasiones en Hispania, una vez en femenino (Tychia: Iruña, VI. CIL II 2936) y dos en masculino, ambos procedentes de Mérida (Badajoz. CIL II 577 + AE 1983, 490 y AE 1983, 493). Su nombre engrosa la lista de los Aelii que figuran sobre textos hispanos como libertos imperiales (CIL II 485, 486, 2646 y AE 1954, 86), aunque no todos son adrianeos como demuestra el texto de Conimbriga (AE 1954, 86), en el que P. Aelius Ianuarius es Augustor(um) libertus.

La restitución del nombre del homenajeado en la primera línea obliga a introducir dos formas abreviadas de nomen y cognomen, cuya anchura viene impuesta por la filiación libertina del dedicante. El desarrollo Sa[turninus] no es el único posible, pero sí el más probable, pues este cognomen es el noveno más frecuente en Hispania, con más de 125 testimonios (ABASCAL 1994, 31). La asociación de Cornelius y Saturninus genera en Hispania hasta 10 casos de homonimia (ABASCAL 1994, 123), aunque no tiene incidencia en el área geográfica que nos ocupa.

En Dianium y su territorium ya conocíamos un grupo de Cornelii, aunque numéricamente no parece importante. A él pertenecen [Q.Cor]nelius Q.filius Gal. Placidus (Denia, Alicante. CIL II 3582) y Q. Cornelius Clemens (Jávea, Alicante. AE 1986, 443); a ellos habría que añadir este testimonio y el del texto $n .^{\circ} 4$ que presentamos a continuación.

Las dos últimas líneas de la inscripción contienen un texto métrico introducido por una causal; la rotura de la cuarta línea impide considerar si se trata de una forma de singular o de plural. Parece claro, no obstante, que estas dos líneas o incluso alguna más hoy perdida, contenían la razón de ser de la dedicación de P. Ael(ius) Ty[chius], aunque la sola presencia del sustantivo (ThLL III.1, 186-189) y la preposición no ofrecen ninguna solución a su desarrollo.

El tipo de letra y el nomen del dedicante parecen indicar que nos hallamos ante un liberto de Adriano, lo que resuelve el problema de la cronología del texto.

La reutilización de materiales y elementos de construcción de época romana y, en concreto, su presencia en estructuras y ámbitos de la ciudad islámica es un fenómeno bastante frecuente en el marco de las intervenciones arqueológicas en Daniya - Denia - . De hecho, fragmentos de fustes y otras piezas de columna, talladas en piedra caliza o en arenisca local, fragmentos de piedra tallada y, en casos muy puntuales, fragmentos escultóricos o epigráficos en piedra, son algunos de los elementos que suelen documentarse, de modo esporádico, en la arqueología árabe de la ciudad.

El hecho de que buena parte del solar de la ciudad romana quede yermo y sin urbanizar a partir del siglo VI d.C. explica el deterioro progresivo de los vestigios de Dianium, debido a la búsqueda y expolio selectivo de estas piezas. 


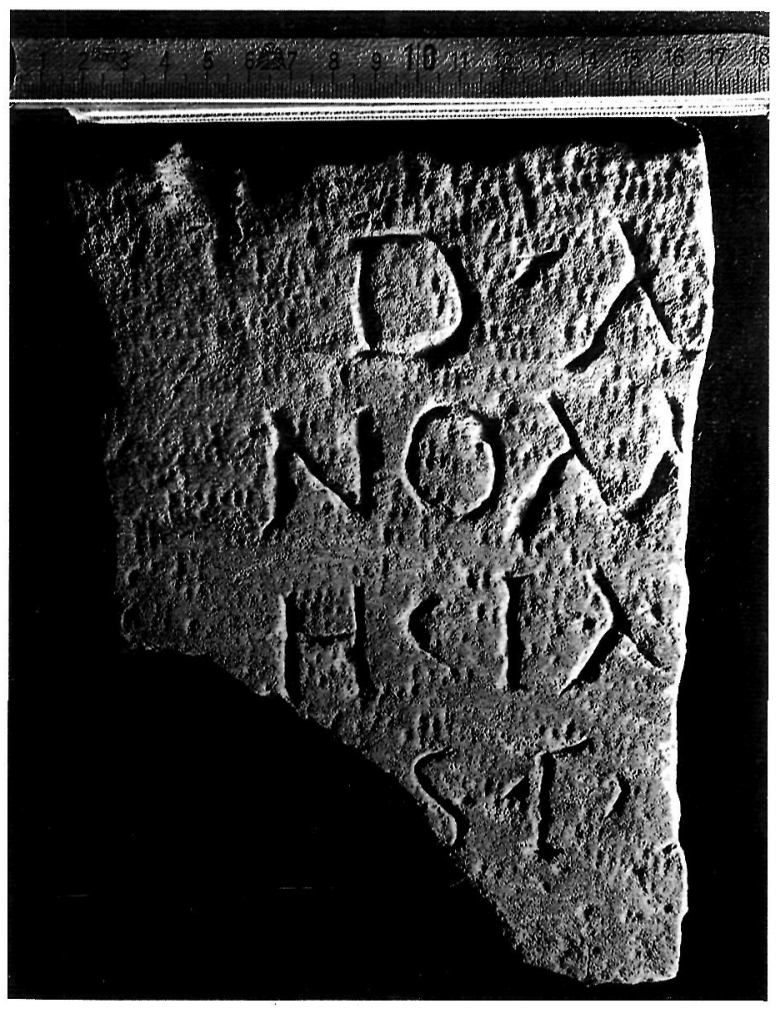

Fig. 9.- Reverso de la inscripción de Sanet i Negrals con el epitafio de Nomas (n. ${ }^{\circ}$ ).

\section{Sanet i Negrals (Alicante. Figuras 8 a 11. GISBERT 1993 a, 23.}

Fragmento de una placa opistógrafa en piedra caliza que sólo conserva el borde superior del soporte original. Fue hallado casualmente por D. José Balaguer Serra en una parcela de Els Canets, del término municipal de Sanet i Negrals.

El lugar de hallazgo es una parcela situada junto al límite de los términos municipales de Pedreguer, Beniarbeig y Sanet i Negrals, al sudeste de este último núcleo. Sus coordenadas

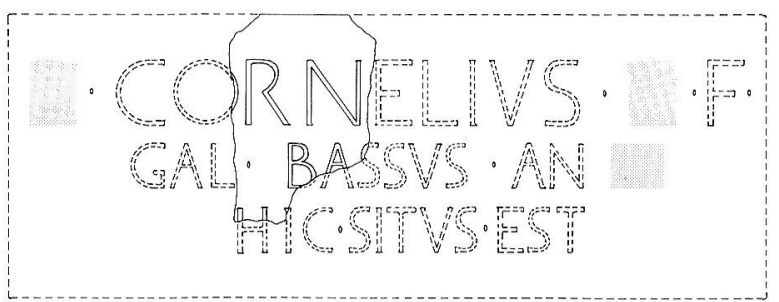

Fig. 10.- Restitución del texto funerario de Cornelius Bassus (n. $\left.{ }^{\circ} 4\right)$.

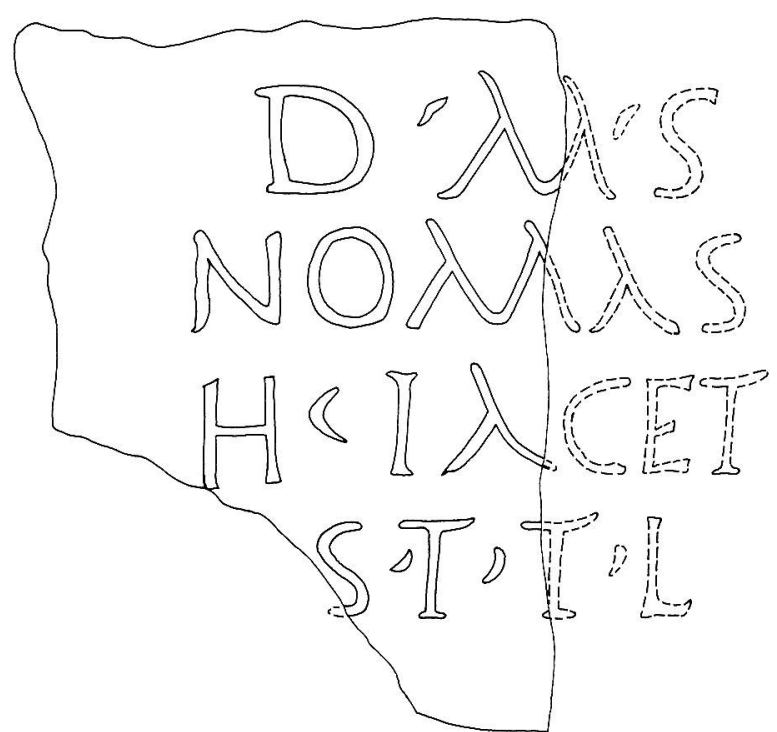

Fig. 11.- Restitución del texto de Nomas (n. $\left.{ }^{\circ} 4\right)$.

son $38^{\circ} 48^{\prime} 27 \gg$ de latitud norte y $3^{\circ} 40^{\prime} 13^{\prime} 0$ de longitud respecto al meridiano de Madrid, Hoja 822 I de la cartografía militar de España 1:25.000. En enclave se halla junto y frente a un conjunto de edificios de los siglos XVIII y XIX conocidos como «Les Ventes de Calderón».

En las parcelas colindantes se han localizado en superficie fragmentos de materiales romanos, entre los que cabe citar ánforas de producción local de tipo Dressel $2 / 4$ y cerámicas comunes, todas ellas datables entre los siglos I y II d.C.; no se han localizado evidencias de construcción o similares que prueben la existencia de una estructura funeraria, y todos los indicios apuntan a un posible establecimiento rural romano que estaría situado en sus proximidades. En este sentido hay que reseñar la cercanía de una villa romana en Les Plantaes (Benidoleig, prov. Alicante) (GISBERT 1990, 26 ss.), que está activa durante todo el Principado, situada sobre la margen derecha del río Girona y a unos 600 metros hacia el sudeste del lugar del hallazgo.

La placa fue empleada como soporte para una inscripción probablemente funeraria en el siglo I d.C. (anverso) y uno de sus fragmentos fue reaprovechado en época tardía con idéntico fin (reverso) .

La rotura derecha del anverso sirvió de borde izquierdo de paginación al texto del reverso, lo que indica que la fractura del texto antiguo ya se había producido cuando fue reutilizada. Mientras el anverso presenta un tratamiento muy cuidado para conseguir una superficie uniforme, su parte posterior debió dejarse sin trabajar, lo que obligó a uniformarla cuando se fue a grabar la segunda inscripción. Para ello se utilizó un 
instrumento corriente pero sin ningún esmero, lo que permite hoy observar sus huellas repartidas por toda la superficie. La falta de tratamiento del reverso en el primer uso de la placa confirma su posición en algún tipo de monumento funerario o pequeño panteón familiar.

No es posible conocer las dimensiones originales del monumento debido a sus notorias fracturas. El fragmento conservado mide $22,5 \times 17 \times 3 ' 6 \mathrm{~cm}$.

El campo epigráfico del anverso mide $17^{\prime} 5 \times 17 \mathrm{~cm}$; el texto está redactado en una capital cuadrada de muy buena factura y sección en $\mathrm{V}$ y las dos líneas conservadas miden 7 y 4'7 cm respectivamente, sin que sea posible conocer las dimensiones de la tercera, en la que aparecen restos de dos trazos verticales y un pequeño ápice lateral. Las interlíneas miden 1'8, 2'2 cm y la única interpunción es un pequeño trazo vertical.

En la primera línea la fractura conserva el surco de una $\mathrm{O}$ circular, y en la tercera, sobre el mismo borde derecho aparece la parte superior de una $\mathrm{S}$. En la tercera línea, el trazo del extremo derecho parece corresponder a un asta, nunca a una $\mathrm{S}$.

El campo epigráfico del reverso mide $16 \times 10^{\prime} 5 \mathrm{~cm}$; el texto está escrito en una cursiva muy irregular, sin demasiado cuidado en la paginación salvo en el centrado de las líneas. La altura de las letras es de 3,2'8, 2' 8 y $2^{\prime} 6 \mathrm{~cm}$; las interlíneas miden $1,1^{\prime} 3$ y $1^{\prime} 3$ y presenta interpunciones irregulares que parecen sugerir trazos oblícuos ligeramente curvos.

El fragmento ingresó por donación de su descubridor en el Museo Arqueològic de la Ciutat de Dènia el 9 de febrero de 1993, en donde lo vimos el 6 de octubre del mismo año. El texto dice:

Anverso:

[-. C]orn[elius -.f.]

[Gal(eria)] Bas[sus an(norum) ---]

h(ic) [s(itus) e(st)]

Reverso:

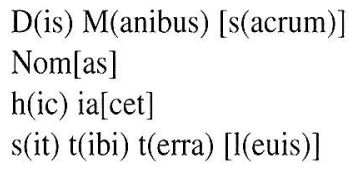

En la inscripción más antigua, que figura sobre el anverso, aparece en la primera línea parte de un nomen aunque, a juzgar por el espacio determinado por el contenido del reverso, debió ser parte de un tria nomina; el cognomen que figura en la segunda línea no parece constituir una filiación, pues probablemente habría sido colocado tras el gentilicio en la primera; más factible es imaginar que en el final de la primera línea y en el comienzo de la segunda figurara una filiación abreviada y la indicación de tribu, con lo que Bassus podría ser el cognomen del difunto; de ahí su restitución en nominativo como el nomen, atendiendo a la antigüedad del fragmen- to, que podría datarse en la primera mitad/mediados del siglo I d.C. Si al comienzo de la segunda línea queda una interpunción que permite imaginar una paginación alineada a la izquierda, mayor problema se genera en su parte posterior, en donde el cognomen debió dejar un espacio libre que sólo pudo ocupar la edad o una improbable indicación de origo. En la tercera línea no parece que pueda suponerse otra cosa que un lacónico $h(i c) s(i t u s) e(s t)$. En la restitución de la tribus al comienzo de la segunda línea hemos considerado que con toda probabilidad debe tratarse de la Galeria, que es la de Dianium y que encaja bien en la cronología del texto.

Sobre los Cornelii de Dianium, vid. lo dicho para la inscripción anterior.

En el texto del reverso la restitución propuesta responde a una paginación centrada a partir de las letras conservadas. El nombre del/de la difunto/a admite posibilidades como Nomas, Nome, Nomeus, Nomice, etc., pero el espacio disponible aconseja optar por el primero. Nomas es un nombre de origen griego ausente hasta ahora en Hispania pero conocido en el repertorio de la ciudad de Roma (SOLIN \& SALOMIES 1988, 1300). La expresión $h$ (ic) iacet, no siendo corriente, es bien conocida en otros textos y no merece comentarios (cfr. CIL II supp., p. 1202); casi todos los testimonios hispanos proceden de la Tarraconense. La formulación inicial y el tipo de letra aconsejan datar este texto en la segunda mitad del siglo II o comienzos del III d.C.

\section{Denia. Inédita. Figura 12.}

Estando ya en prensa este trabajo, se ha descubierto en Denia un nuevo fragmento de inscripción funeraria que debemos incluir aquí fuera de su posición lógica tras el texto n. ${ }^{\circ} 3$. El hallazgo se produjo al realizar las obras de reforma de la «Barra Llarga», pues se encontraba reaprovechado en un muro

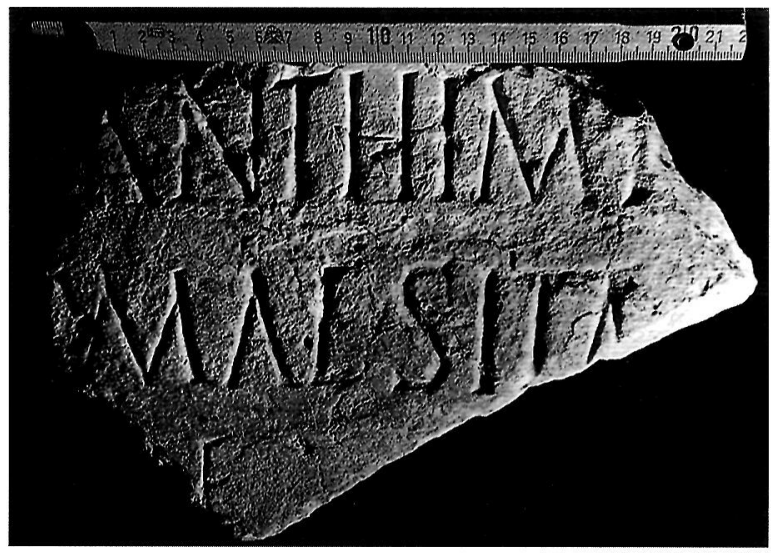

Fig. 12.- Inscripción de Anthima en Denia (n. ${ }^{\circ}$ 5) 
perimetral del edificio situado en el n. ${ }^{\circ} 31$ de la calle Pont; la construcción de esta casa puede datarse en el siglo XVIII, momento en que la calle experimenta una expansión urbanística notable.

El soporte es un fragmento de caliza marmórea rosada de Buixcarrot, con la superficie muy gastada, vetas cristalizadas y restos de argamasa adheridos como consecuencia de su empleo como material de construcción. Pertenecía a una losa, alisada sin esmero por su parte posterior, y sus dimensiones actuales son $18 \times 28 \times 77^{\prime} 5 \mathrm{~cm}$. El campo epigráfico es de $16^{\prime} 5 \times 25 \mathrm{~cm}$. Conserva tres líneas, aunque no es posible conocer su posición en el texto, y de la línea inferior sólo queda una vocal. La altura de las letras es de 4'5, 4'5 y $3^{\prime} 5 \mathrm{~cm}$ respectivamente, con una interlínea de 2'2/2'5.

En la primera línea de texto queda a la derecha un asta oblícua perteneciente a una $\mathrm{A}$, aunque en ambos sentidos se han perdido letras; en la segunda línea se observa a la izquierda el arco de una $\mathrm{O}$ delante de la consonante, mientras por la derecha no hay trazos visibles después de la vocal. En la tercera línea sólo se conserva una $\mathrm{E}$ con $6 \mathrm{~cm}$ sin texto a su derecha, que no es una abreviatura, pues a su izquierda aparece la parte superior de un pequeño trazo vertical. Sólo queda huella de una interpunción en el centro de la segunda línea.

El fragmento del monumento se conserva ya en el Museo Arqueològic de la Ciutat de Dènia, en donde ingresó por donación de la empresa Drassanes S.L. a través de D. Santiago Boluda el 10 de diciembre de 1993. El texto dice:

$$
\begin{aligned}
& {[--]} \\
& {[--] \text { Anthima }[--]} \\
& {[--- \text { R]omae sita }[---]} \\
& {[---]+\text { E [---] }} \\
& {[---]}
\end{aligned}
$$

Desde el punto de vista del contenido en el texto sobresalen dos aspectos: el estrictamente onomástico y la referencia a la defunción en Roma.

Respecto al primero, Anthima aparece por vez primera en los repertorios hispanos, en los que sólo conocíamos dos testimonios de Anthimus con diferentes grafías sobre textos de Valentia (Anthimus. AE 1979, 370) y Elvas (conc. Elvas, Portoalegre) (Anthymus. CIL II 152). En el repertorio itálico figura el masculino Anthimas (SOLIN 1982, 1079), aunque la inscripción de Dianium con el participio de la segunda línea despeja toda duda sobre el género de la difunta. Antima/-us, Anthymus son algunos de los cientos de antropónimos griegos que portan los libertos en las áreas más prósperas del occidente latino durante el Principado, especialmente en núcleos urbanos o en sus proximidades.

La defunción de Anthima en Roma y su correspondiente sepelio en aquella ciudad llevó a sus familiares, allegados o miembros del mismo colegio funeraticio a honrar su memoria en Dianium con la dedicación de una inscripción. La defunción fuera del ámbito geográfico ordinario figura con cierta frecuencia en inscripciones; sólo los índices de CIL II (supp. p. 1199) dan fe de un buen número de expresiones como defunctus llici (CIL II 3181), in Phrygia decessit (CIL II 4616), peregre defunctus (CIL II 3076, 4064, 4065), etc. Una inscripción de Complutum (CIL II 3035 + P. 1042; ABASCAL y FERNÁNDEZ-GALIANO 1984, 21, n. ${ }^{\circ}$ 18) dice [ur]be Italia d[ef]uncto [--]. La comparación expresa del texto de Dianium se puede hacer con un epígrafe segobricense en el que Aur(elius) Pyrron figura como defunctus Roma(e) (HEp 1, 328). A diferencia de aquel texto, el de Dianium contiene la grafía correcta del locativo.

La referencia a esta muerte de Anthima fuera de su patria probablemente puede considerarse una evidencia de que esta es sólo una de las dos inscripciones que honraron su memoria: la una en Roma, la otra en Dianium; aquella pudo ser una simple placa en un panteón colectivo o un texto de más envergadura adaptado al tamaño de la sepultura; la inscripción de Dianium no revela ninguna de estas características porque sólo es un recuerdo. La duplicidad de textos funerarios y honoríficos referidos a un mismo personaje no sólo se constata en casos tan específicos como éste: incluso dentro de un mismo territorium no es difícil encontrarlos (STYLOW 1985, 661).

El lugar de hallazgo de este nuevo documento está situado a unos 150 metros al nordeste de una domus altoimperial (GISBERT 1993 b, 213 s.) identificada en el perímetro urbano actual como «Prolongación Temple Sant Telm» y de una zona de reciente colmatación que, con anterioridad, era un área de dunas relacionada con el fondeadero o puerto de Dianium (GISBERT 1985, 66 s.). La relación anchura/altura de las letras, la inclinación de los brazos de la $\mathrm{M}$ y la ligera inclinación de los trazos horizontales de T y E aconsejan datar la inscripción en los años centrales o segunda mitad del siglo II d.C.

\section{BIBLIOGRAFÍA}

ABAD, L. y ABASCAL, J.M., 1991: Textos para la historia de Alicante, Historia Antigua, Alicante, 1992.

ABASCAL, J.M., 1994: Los nombres personales en las inscripciones latinas de Hispania, Murcia-Madrid, 1994.

ABASCAL, J.M. y FERNÁNDEZ-GALIANO, D., 1984: «Epigrafía Complutense», Museos 3, 1984, 7 ss.

ALFÖLDY, G., 1987: Römisches Städtewesen auf der neukastilischen Hochebene. Heidelberg.

FITA, F., 1908: «Inscripciones romanas y griegas de Cartagena, Almazarrón, Pego, Valera, Herramelluri, Córdoba, Vélez Rubio y Vera», BRAH 52, 508-509.

GISBERT, J.A., 1980: «Pego. Notes d’Arqueología romana». Fiestas de Pego. Pego, 2 páginas.

- 1985: «Investigación arqueológica en la ciudad de Dianium. Estado de la cuestión», Campus [Alicante] 7, 66-68.

- 1990: «Les Plantaes, Benidoleig». Excavacions arqueologiques 
de salvament a la Comunitat Valenciana 1984-1988. Vol. II: Intervencions rurals, Valencia, 26-30.

- 1993 a: «Hallazgo de una inscripción romana en Sanet i Negrals», Diario Canfali Marina Alta, sábado, 27 de febrero de 1993, pág. 23.

- 1993 b: «Balsamario con representación de Mercurio en una domus de Dianium, Denia (Alicante)», en J. Arce (ed.), Bronces y religión romana, Madrid 213-227.

MAULEON, M" D., 1983: Índice de las inscripciones latinas publicadas en el Boletín de la Real Academia de la Historia (1877. 1950). Pamplona.
RABANAL, M.A. y ABASCAL, J.M., 1985: «Inscripciones romanas de la provincia de Alicante», Lucentum 4, 191-244.

SOLIN, H., 1982: Die griechischen Personennamen in Rom. Ein Namenbuch. Berlín.

SOLIN, H y SALOMIES, O., 1988: Repertorium nominum gentillum et cognominum Latinorum. Hildesheim.

STYLOW, A.U., 1985: «Organización territorial romana en el valle de Los Pedroches (conuentus Cordubensis)» XVII Congr. Nac. Arq. Logroño 1983, Zaragoza 1985, 657-666.

ThLL, 1976: Thesaurus Linguae Latinae. Vol. IIT.I. Leipzig. 